\title{
EFFECT OF MODIFIED ATMOSPHERE PACKAGING (MAP) AND POSTHARVEST TREATMENTS ON QUALITY OF LITCHI FRUITS DURING STORAGE
}

\author{
Pham Thi Thu Ha ${ }^{1,}$, Nguyen Thi Mien ${ }^{1}$, Duong Thu Hien ${ }^{2}$, Nguyen Thanh Tung", \\ Nguyen Thi Trang ${ }^{2}$, Nguyen Thu Huong ${ }^{2}$ \\ ${ }^{1}$ Institute of Chemistry, VAST, 18 Hoang Quoc Viet, Cau Giay, Hanoi \\ ${ }^{2}$ Lac Trung Technology and Trading Service Company Limited, 350 Lac Trung, Hai Ba Trung, \\ $\mathrm{Ha} \mathrm{Noi}$ \\ ${ }^{3}$ Natural Science Faculty, Hai Duong College, Lien Hong, Gia Loc, Hai Duong \\ "Email: haptt6@gmail.com
}

Received: 19 August 2016; Accepted for publication: 19 April 2017

\begin{abstract}
In this article, effect of modified atmosphere packaging (MAP) and different postharvest treatments on quality of litchi (Litchi chinensis Sonn.) fruit was investigated. Quality indexes of litchi during cold storage at $4 \pm 1{ }^{0} \mathrm{C}$ were measured in terms of decay, total soluble solids, titratable acidity, color, anthocyanin content and incidence of microbiological infection. These indexes were determined at harvest and 7, 14, 21, 28 and 35 days after storage. The results suggested that after 35 days of storage, the pericarp browning and fruit quality deterioration can be improved compared to the control by dipping fruit in hot water at $47{ }^{\circ} \mathrm{C}$ in $7 \mathrm{~min}$., followed by oxalic acid solution ( $\mathrm{pH}=3$ in $6 \mathrm{~min}$.) and finally packed in MAP bag (LDPE, thickness of $30 \mu \mathrm{m}$ incorporated $3-5 \%$ silica additive) and stored at $4 \pm 1{ }^{\circ} \mathrm{C}$ and relative humidity of $90 \%$.
\end{abstract}

Keywords: litchi, modified atmosphere packaging, postharvest treatment, storage, fruit quality.

\section{INTRODUCTION}

Litchi (Litchi chinensis Sonn.) is a tropical to subtropical fruit, highly admired for its characteristic appealing bright red color, delicious taste, and attractive aroma, were grown in Luc Ngan district, Bac Giang province of Vietnam. However, the litchi fruits are consumed mainly in the domestic market, exported partially $(5-10 \%)$ to the close markets such as Southeast Asian countries, Australia, etc.[1]. Pericarp browning, desiccation and postharvest decay have been identified as major problems which greatly reduce its market value around the globe.

Previous studies have shown that the pericarp browning of the litchi fruit is related to the oxidation of phenolic compounds by peroxidase (POD) and polyphenol oxidase (PPO), membrane lipid peroxidation, degradation of anthocyanins, and redox imbalance resulting from overproduction of reactive oxygen species (ROS) and decreased antioxidant capacity. Therefore, 
the inhibition of these physiological processes could be important for controlling the pericarp browning and extending the shelf life of harvested litchi fruit. The litchi industry commercially uses sulphur dioxide $\left(\mathrm{SO}_{2}\right)$ fumigation to overcome these problems. However, $\mathrm{SO}_{2}$ fumigation leaves undesirable residues, alters the fruit taste, and results in health hazards for consumers and pack house workers [2].

Many studies have shown that pericarp color was maintained well by dipping in dilute acid solution (at low pH). Either treatment with acid solution such as oxalic acid, chlohydric acid, citric acid, ascorbic acid... or combining acids and chitosan was significantly inhibited PPO enzyme activity and maintained anthocyanin in pericarp at high level. Among them, treatment with oxalic acid solution controlled pericarp browning the best due to increasing uniformity of the cell membrane and inhibiting activity of PPO enzyme during storage. Moreover, oxalic acid is a natural antioxidant and a metabolic product that is distributed among different organs of plants, play an important role in the natural and artificial preservation of oxidized materials [3$5]$.

In addition, the approaches which inhibit the growth of microorganisms have been investigated. Using synthesis antifungal incorporated cooling is a highly effective method. However, if the treatment method, dosage and isolation duration etc. were not controlled strictly, it could be harmful to humans and the environment. Hot water treatment (by spraying, dipping or brushing...) not only slow the growth of pathogens but also inhibit the possibility of infection of fruits. This method can be alternative to sulphur-dioxide fumigation method, applied easily at commercial scale, not affect human health. Combined with acid treatment obtained more safe and higher quality litchi fruits [6].

Modified atmosphere packaging (MAP) is the best method for litchi fruit preservation and storage. The successful use of MAP is based on the specific permeation properties of polymer films to $\mathrm{O}_{2}$ and $\mathrm{CO}_{2}$ to generate atmospheres that are suitable for the postharvest life of many horticultural commodities. This technology also provides three advantages: (1) it helps to reduce browning, (2) to control postharvest diseases and (3) it maintains a high humid environment for litchi fruit inside the sealed plastic film [5].

In previous studies, the effect of various MAP materials on postharvest quality retention of litchi has been investigated. The results showed that there are insignificant difference in the quality litchi between storing in MAP bags produced by the Institute of Chemistry and CE44 bags from Korea after 4 weeks storage. The weight loss of fruits packed in these film was $4.37 \%$ and $4.24 \%$, respectively. While the incidence of decay of fruits packed in PE (with the same thickness) is $100 \%$ after 4 weeks storage [7]. The objective of this study was to investigate various postharvest treatment methods combined with packaging in MAP to reduce incidence of microbiological infection, extend shelf-life and maintain, improve sensory quality and the commercial value of litchi fruit.

\section{MATERIALS AND METHODS}

\subsection{Materials}

- Litchi (Litchi chinensis Sonn.) fruits which were harvested in Quy Son commune, Luc Ngan district, Bac Giang province, reached harvest maturity 2 (80 - 85 days after full bloom). In the study, chlohydric acid, citric acid, oxalic acid, standard sodium hydroxide solution, phenolphthalein (China). Modified atmosphere packaging (MAP) bags, the commercial product with GreenMAP trademark, was manufactured in Institute of Chemistry, Vietnam Academy of 
Science and Technology from polyethylene incorperated 3 - $5 \%$ silica additive. The thickness of the bags was $30 \mu \mathrm{m}$ ( size $25 \mathrm{~cm} \times 30 \mathrm{~cm})$.

\subsection{Postharvest treatment}

Litchi fruits were harvested, subjected to preliminary hydro-cooling $\left(0{ }^{\circ} \mathrm{C}\right)$ by keeping in insulated container containing ice and transported to laboratory within $4-6 \mathrm{~h}$. Fruits of uniform size with the length of stalk $2-3 \mathrm{~mm}$, free off physical damage, injury caused by insects and fungal infection were selected. The experiment samples were listed as follows:

(CT1) - Control, fruits were untreated

(CT2) - Fruits were dipped in hot water at $47{ }^{\circ} \mathrm{C}$ for 7 minutes

(CT3) - After treating with hot water, fruits were dipped in hydrochloric acid solution

(CT4) - After treating with hot water, fruits were dipped in citric acid solution

(CT5) - After treating with hot water, fruits were dipped in oxalic acid solution

For applying hot water treatment, the fruits were dipped in hot water kept at $47{ }^{\circ} \mathrm{C}$ for 7 min., air dried $\left(18-20{ }^{\circ} \mathrm{C}\right)$. For applying hot water treatment and different acids, hot water treated fruits were dipped in $\mathrm{pH} 3$ acid solutions for $6 \mathrm{~min}$., air dried $\left(18-20{ }^{\circ} \mathrm{C}\right)$. The air dried fruits were distributed into groups of $2 \mathrm{~kg}$ and then placed inside the MAP bags, kept for observations under cold storage conditions $\left(4 \pm 1{ }^{\circ} \mathrm{C}\right)$. Each experiment had three replicates. Fruits from each replication were taken for determine changes of terms of decay, total soluble solids, titratable acidity, color, anthocyanin content and incidence of microbiological infection after $7,14,21,28,35$ days of storage and the end result was the average value.

\subsection{Methods}

\subsubsection{Decay}

Decay was defined as the ratio of decayed fruit weight (fruits were caused of fungi, pericarp browning, physical damage) and initial fruit weight.

\subsubsection{Total soluble solids content}

Total soluble solids content is determined according to TCVN 7771:2007 standard using a digital refractometer (PR-101 Atago, Japan).

\subsubsection{Titratable acidity content}

Total acidity content is determined according to TCVN 5483-91 standard using the automated voltage titration device Titrino 702SM, Metrohm (Switzerland).

\subsubsection{Color}

Color of the whole litchi fruit was measured by a ColorTec 5974-01 Colorimeter (Mexico) and the results were expressed as $\mathrm{L}, \mathrm{a}, \mathrm{b}$ (Hunter value). The " $\mathrm{L}$ " scale ranges from no reflection, i.e., black $(\mathrm{L}=0)$ to perfect diffuse reflection, i.e., white $(\mathrm{L}=100)$. The "a" scale ranges from negative values for green $(-60)$ to positive values for red $(+60)$, and the " $b$ " scale ranges from negative values for blue $(-60)$ to positive values for yellow $(+60)$.

$\Delta \mathrm{E}$ color index indicates the level difference in the pericarp color of stored fruits and the pericarp color of initial fruits, $\Delta \mathrm{E}=\sqrt{\Delta L^{2}+\Delta a^{2}+\Delta b^{2}}$. 


\subsubsection{Anthocyanin content}

Anthocyanin content was determined by differential $\mathrm{pH}$ method (AOAC Official Method 2005.02).

\subsubsection{Incidence of microbiological infection}

Incidence of microbiological infection index was assessed by using the scale (Table I). The method outlined by Khan et al. [8] was used to determine this index.

Table 1. Scales used for incidence of microbiological infection index.

\begin{tabular}{|c|c|}
\hline Scale & Incidence of microbiological infection \\
\hline 1 & no fruit infected \\
\hline 2 & $0-5 \%$ infected fruits \\
\hline 3 & $5-10 \%$ infected fruits \\
\hline 4 & $10-25 \%$ infected fruits \\
\hline 5 & $25-50 \%$ of infected fruits \\
\hline 6 & $50 \%$ of infected fruits \\
\hline
\end{tabular}

\section{RESULTS AND DISCUSSION}

\subsection{Decay}

Table 2. Effect of treatments on the decay (\%).

\begin{tabular}{|c|c|c|c|c|c|}
\hline Samples & 1 & 2 & 3 & 4 & 5 \\
\hline CT1 & $3.21 \pm 0.17$ & $5.14 \pm 0.81$ & $8.75 \pm 0.25$ & $12.61 \pm 1.12$ & $17.52 \pm 1.24$ \\
\hline CT2 & $2.91 \pm 1.08$ & $3.76 \pm 0.55$ & $4.62 \pm 0.31$ & $6.32 \pm 0.93$ & $9.73 \pm 1.34$ \\
\hline CT3 & $4.75 \pm 0.72$ & $5.62 \pm 0.47$ & $6.48 \pm 0.19$ & $8.21 \pm 1.05$ & $11.66 \pm 0.98$ \\
\hline CT4 & 0.00 & 0.00 & $4.05 \pm 0.52$ & $6.28 \pm 0.37$ & $8.32 \pm 2.31$ \\
\hline CT5 & 0.00 & 0.00 & $3.63 \pm 0.36$ & $5.62 \pm 0.22$ & $7.45 \pm 1.34$ \\
\hline
\end{tabular}

Decay is an important indicator to determine if the preservation methods is successful. Results are presented in Table 2.

The results showed that the pretreatment methods before storage significantly reduces the rate of deterioration compared with using only modified atmosphere packing (MAP). However, there is a difference about the effectiveness of each method for pretreatment process.

Actual observations showed that the hot water treatment is able to limit the development of pathogenic mold, fungi and microorganisms on pericarp, but it didn't limit the pericarp browning. Process should be a certain percentage of fruit damaged by pericarp browning. Litchi fruits being treated with hydrochloric acid solution are nice red. However, because the litchi is fruit wood pericarp, easily subjected to strong acids leading to softening of shells and there are many cracks which lost market value since the first weeks of storage. Meanwhile, the structure 
of pericarp of litchi fruits which were pre-treated with a solution of citric acid and oxalic acid did not change. In addition, they still showed good performance, i.e. valuable hardness and relatively good sense.

\subsection{Total soluble solids}

Total soluble solids (TSS) is one of the important indicators to determine the quality during storage of litchi. The change of TSS in the preservation process is shown in Figure 1.

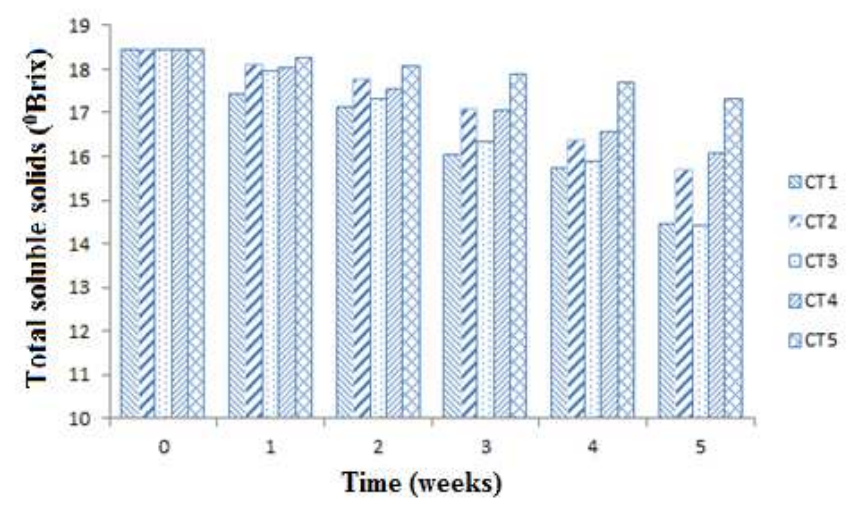

Figure 1. Effect of the treatment methods on the total soluble solids content.

The total soluble solids content trends to decrease during storage, due to these substances are still taking part in the process of metabolism to maintain the life of the fruit. However, the TSS content went down insignificantly and there wasn't the difference between the samples treated with different agents. After 3 weeks storage, the rate of change of TSS content in most of the samples tends to be significantly increased. After 5 weeks of storage, the TSS content in CT5 least reduced (approximately $94 \%$ compared the initial value) and decreased the most in CT1 (about $79 \%$ from the initial state).

\subsection{Titratable acid}

The goal of preservation is to reduce to a minimum the loss of organic acid content in the litchi to maintain the sensory value of the fruit. Results of studying the total acid content in the preservation process is shown in Figure 2.

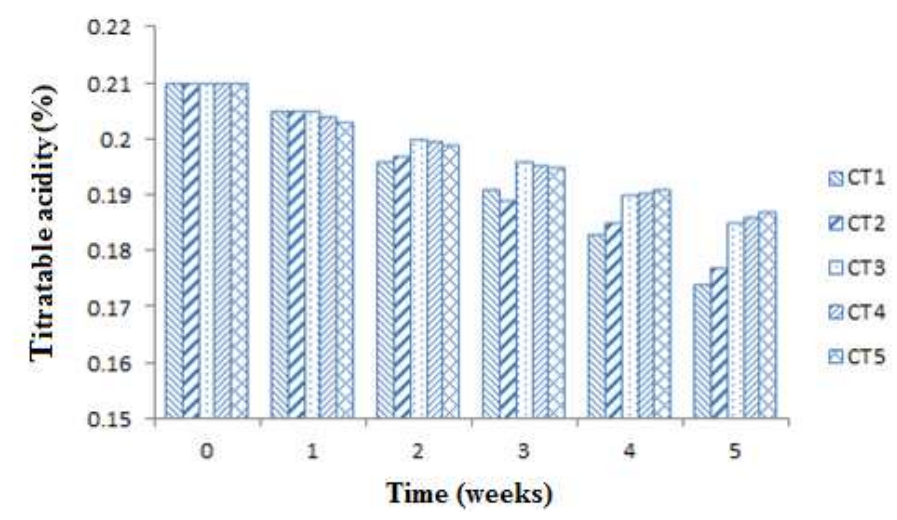

Figure 2. Effect of the treatment methods on the change of titratable acid content. 
In the process of preserving, the total acid content tends to decrease, which proved partly flesh had been transformed. However, after the first 2 weeks of storage, the difference of the total acid content in the samples is negligible. The total acid content in the fruit treated with acid solution remain around $88 \%$ - $90 \%$ from the initial value after 5 weeks of storage. This result is consistent with the report by Khan et al. [8] studying the preserving litchi on the cool condition.

\subsection{Color}

For litchi, the color is the first criterium of evaluation affecting the purchase decisions of consumers. In the process of preserving, the litchi fruit pericarp tended to be browning that leads to their commercial viability to be a serious decline. The results of the effects of treatment methods to change the color of the pericarp is presented in Table 3.

Table 3. Effect of treatment methods on the color change of pericarp $(\Delta \mathrm{E})$.

\begin{tabular}{|c|c|c|c|c|c|c|}
\hline Samples & 0 & 1 & 2 & 3 & 4 & 5 \\
\hline CT1 & 0 & $2.81 \pm 0.16$ & $5.31 \pm 0.09$ & $8.25 \pm 0.27$ & $11.90 \pm 0.37$ & $16.18 \pm 0.54$ \\
\hline CT2 & 0 & $2.71 \pm 0.24$ & $5.42 \pm 0.15$ & $7.90 \pm 0.51$ & $10.38 \pm 043$ & $15.34 \pm 0.31$ \\
\hline CT3 & 0 & $2.38 \pm 0.11$ & $4.56 \pm 0.20$ & $6.89 \pm 0.23$ & $9.02 \pm 0.64$ & $13.27 \pm 0.16$ \\
\hline CT4 & 0 & $1.95 \pm 0.18$ & $3.89 \pm 0.36$ & $5.72 \pm 0.34$ & $8.13 \pm 0.31$ & $11.16 \pm 0.41$ \\
\hline CT5 & 0 & $1.01 \pm 0.21$ & $2.01 \pm 0.13$ & $3.84 \pm 0.07$ & $5.67 \pm 0.15$ & $9.33 \pm 0.32$ \\
\hline
\end{tabular}

During the storage period, the pericarp browning increased with increasing period of storage because PPO enzyme decaying the anthocyanins, thus forming brown-color by-products. The higher value of $\Delta \mathrm{E}$, the higher the color change.

The results showed that the $\Delta \mathrm{E}$ index tends to increase in all the samples in the preservation process. After 5 weeks of storage, the $\Delta \mathrm{E}$ indexes of the samples which were treated with organic acid solution were lowest. This result proves the effect of the treatment process with acid in the maintenance of pericarp color due to the activity of the PPO enzyme was inhibited at low $\mathrm{pH}$ levels, so the color change of the litchi fruit occurs more slowly. In addition, the red color of the samples treated with hydrochloric acid solution remain good, but because of the influence of microorganisms, the brightness of pericarp was not maintained such as the fruits which were dipped with citric and oxalic acid solution.

\subsection{Anthocyanin content}

The pericarp browning phenomenon of litchi occurs mainly due to the oxidation of anthocyanin compounds forming brown products under the effect of the PPO enzyme, $\mathrm{O}_{2}$ and $\mathrm{H}_{2} \mathrm{O}_{2}$ which is produced when vitamin $\mathrm{C}$ is decomposed. The analytical results of the anthocyanin content in pericarp during storage is shown in Figure 3. 


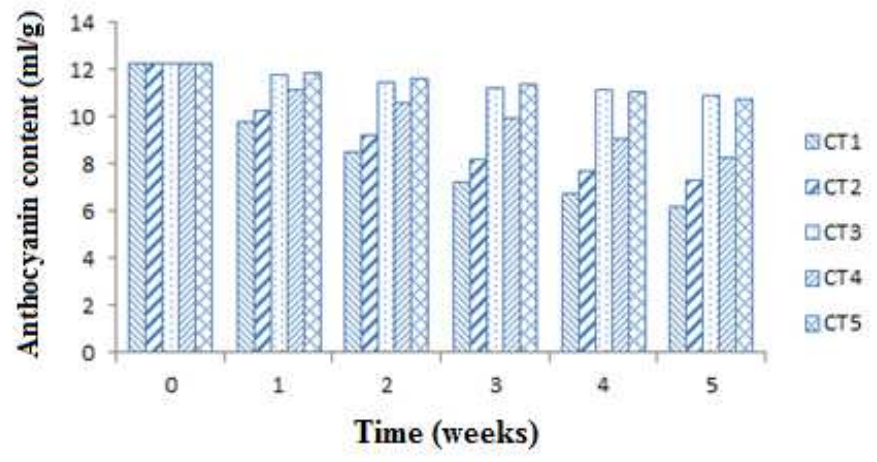

Figure 3. The effect of treatment methods on the anthocyanin content.

It can be seen that the anthocyanin content decreases during the storage period, especially CT1, CT2 and CT4. The reduction of the anthocyanin content in CT3 and CT5 is not significant and this value is maintained at a high level after 5 weeks of preservation. Oxalic acid is oxidized easily by $\mathrm{H}_{2} \mathrm{O}_{2}$, this process competes with the oxidation reaction of anthocyanin. So it helps the red color of pericarp remain for more long time than the fruits treated with citric acid solution.

\subsection{Incidence of microbiological infection}

The diseases caused by microorganisms is a major cause of reduced the storage period and commercial value of litchi. The results of studying the growth of diseases caused by microorganisms during storage are shown in Table 4.

Table 4. The effect of the treatment methods in the development of diseases caused by microorganisms.

\begin{tabular}{|c|c|c|c|c|c|c|}
\hline Samples & 0 & 1 & 2 & 3 & 4 & 5 \\
\hline CT1 & 1.0 & 2.0 & 2.5 & 3.0 & 3.5 & 4.0 \\
\hline CT2 & 1.0 & 1.0 & 1.0 & 2.0 & 2.0 & 2.5 \\
\hline CT3 & 1.0 & 2.0 & 3.0 & 3.5 & 4.0 & 4.5 \\
\hline CT4 & 1.0 & 1.0 & 1.0 & 1.5 & 2.0 & 2.0 \\
\hline CT5 & 1.0 & 1.0 & 1.0 & 1.0 & 2.0 & 2.0 \\
\hline
\end{tabular}

The results showed that after 2 weeks of storage, the disease indicators in CT2, CT4 and CT5 are similar when harvested fruit. After 5 weeks of storage, the disease indicators in CT4 and CT5 increased up only 2 points (corresponding to $<5 \%$ of the pericarp is infected). The sample treated with hydrochloric acid solution (CT3) have signs of cracking, so microorganisms can penetrate easily, causing increased the amount of infected fruits.

\section{CONCLUSIONS}

The results showed that treatment of litchi by hot water at $47{ }^{\circ} \mathrm{C}$ for $7 \mathrm{~min}$., then dipped in a oxalic acid solution ( $\mathrm{pH}=3$ for 6 min.), finally packed in MAP bags with the thickness of $30 \mu \mathrm{m}$ (incorporated 3-5\% silica additives) and stored at $4 \pm 1{ }^{\circ} \mathrm{C}, 90 \%$ humidity can extend the storage time to 35 days (5 weeks) at the decay incidence $<10 \%$, the quality of fruit change insignificantly compared initial state, color pericarp is of stability and low disease index. 
This result is the basis for preserving postharvest litchi on a large scale, helping to extend shelf life, maintaining fruit quality, suitable for the storage and transport over long distances.

Acknowledgement. Authors would like to thank Vietnam Academy of Science and Technology and Bac Giang Department of Science and Technology for providing financial support to conduct this research (VAST.NĐP.16/15-16 topic).

\section{REFERENCES}

1. "Thi truong trai vai Viet Nam va trien vong xuat khau ra the gioi", http://iasvn.org/homepage/Thi-truong-trai-vai-Viet-Nam-va-trien-vong-xuat-khau-ra-thegioi-6809.html. 26/5/2015.

2. Paull R. E., Reyes M. E. Q., Reyes M. U. - Sulfite residues on litchi fruit treated with sulfur dioxide, Postharvest Biology and technology 14 (1998) 229-233.

3. Sun D., Liang G., Xie J., Lei X., Mo Y. - Improved preservation effects of litchi fruit by combining chitosan coating with ascorbic acid treatment during postharvest storage, African Journal of Biotechnology 9 (22) (2010) 3272-3279.

4. Wu B., Li X., Hu H., Liu A., Chen W. - Effect of chlorine dioxide on the control of postharvest diseases and quality of litchi fruit, African Journal of Biotechnology $\mathbf{1 0}$ (2011) 6030-6039.

5. Sivakumar D., Korsten L. - Influence of modified atmosphere packaging and postharvest treatments on quality retention of litchi cv. Mauritius, Postharvest Biology and technology 41 (2006) 135-142.

6. Marboh E. S., Lal R. L., Mishra D. S., Goswami A. K. - Effect of hot water treatment and oxalic acid on colour retention and storage quality of litchi fruit cv. Rose Scented, Indian J. Hort. 69 (4) (2012) $484-488$.

7. Pham Thi Thu Ha, Dinh Gia Thanh, Nguyen Thi Trang, Duong Thu Hien, Pham Thi Thu Trang, Nguyen Thanh Tung - Effect of modified atmosphere packaging (MAP) on postharvest quality retention of litchi, Tạp chí Khoa học và Công nghệ $\mathbf{5 3}$ (4D) (2015) 382-388.

8. Khan A.S., Ahmad N., Malik A. U., Amjad M. - Cold storage influences the postharvest pericarp browning and quality of litchi, International Journal of Agricultural and Biological Engineering 14 (2012) 389-394. 